\title{
Plastic rotation capacity of high-strength concrete beams
}

\author{
S. M. R. Lopes ${ }^{1}$ and L. F. A. Bernardo ${ }^{2}$ \\ (1) Faculdade de Ciências e Tecnologia da Universidade de Coimbra, Portugal. \\ (2) Universidade da Beira Interior, Covilhã, Portugal.
}

Paper received: April 20, 2001; Paper accepted: January 2, 2002

\section{A B S T R A C T}

This work describes an experimental study on the plastic rotation capacity of high strength beams. Nine simply supported isostatic beams were tested, by applying comprising two symmetrical concentrated loads at approximately one-third and two-third's span. A method of analysis is defined that leads to the development of a parameter that characterizes the plastic rotation capacity at the failure section by means of a plastic analysis of the tested beams. The influence of concrete strength and the longitudinal tensile reinforcement ratio on the capacity for plastic rotation is examined and discussed. The results are discussed and compared with previous studies.

\section{R É S U M É}

Ce travail décrit une étude expérimentale sur la capacité de rotation plastique de poutres en béton à haute résistance. Neuf poutres isostatiques ont été testées avec une charge constituée par deux forces concentrées et symétriques situées environ au tiers et aux deux tiers de la portée. Une méthode d'analyse est définie, conduisant au développement d'un paramètre qui caractérise la capacité de rotation plastique de la section de rupture, utilisant une analyse plastique des poutres testées. L'influence de la résistance du béton et du taux d'armatures longitudinales de traction sur la capacité de rotation plastique est examinée et discutée. Les résultats sont analysés, discutés et comparés avec des études antérieures.

\section{INTRODUCTION}

Research work conducted in recent years has improved our knowledge of the potential of mixtures of chemicals and minerals. This knowledge has made it possible to manufacture concretes with high mechanical properties, with successive improvements with regard to workability and durability. It has been found that high-strength reinforced concrete is particularly competitive in many structures, such as long span bridges, where strength, durability and service behaviour are particularly important.

Given its considerable advantages over normalstrength concrete, the use of high-strength concrete has increased rapidly in the last ten years and it is inevitable that it will come to be used in other areas of construction in the near future.

It is widely known that concrete becomes less deformable and more brittle when its compressive strength increases. Some previous tests [5] aimed to study axial and lateral strain with increasing stress applied in compression tests on normal density concretes of varying strengths. These studies showed that lowstrength concretes only developed a modest level of stresses, but, on the other hand, they succeeded in maintaining that level for an appreciable period under strain. For their part, high-strength concretes attained a considerably higher level of stress, but could not sustain it for a significant period under strain. The load-bearing capacity of high-strength concretes fell sharply from the stressstrain ratio peak. This behaviour clearly illustrates the brittle nature of high-strength concretes.

The finding that high-strength concretes are more brittle at first raised serious reservations, particularly with respect to knowing whether structural members made from high-strength concretes would be sufficiently ductile. Doubts on this score led to restrictions being placed on the use of high-strength concretes as building materials, especially for constructions located in areas at high risk of seismic activity. Greater brittleness of the concrete indicated that structures made from this type of concrete would have a limited rotational capacity. Using high-strength concrete, these geological regions would 
obviously depend on the sufficient inelastic deformability of the structural elements under cyclical loads of the type caused by seismic excitation. Acceptable behaviour naturally depends directly on the adequate rotational capacity of the critical sections.

It was also found that the low deformability of highstrength concrete does not necessarily result in the low deformability of members made from this material, which combine the relative brittleness of the concrete material with reinforcement elements.

The theory of plasticity is today an integral part of structural mechanics. The validity of the theory of plasticity presupposes a ductile behaviour on the part of the structure, so that this may adapt itself to the redistribution of internal forces admitted in the calculation of ultimate limit states, without a premature brittle failure occurring. During recent years, many experimental tests have clearly demonstrated that properly reinforced concrete exhibits quite a significant capacity for deformation. This is broadly enough, in general, to allow the theory of plasticity to be applied. Everything points towards structural elements made using high-strength concretes, with the proper reinforcements, also exhibiting a good capacity for deformation. For these elements, however, the rules on the details could differ from the rules adopted for elements made with normal-strength concretes.

The capacity of a structural member to exhibit considerable deformation in its critical sectors is directly related to the ductility indicated for that member. Ductility is defined as the capacity of a material, section, structural member or structure to sustain plastic deformation without a substantial drop in its load-bearing capacity. This is a very important property, since it is directly related to structural safety and the capacity to redistribute internal forces. This latter point is considered to be extremely important today, especially in continuous structural members.

The redistribution of moments relies on the fact that there be sufficient ductility in the regions of what are known as plastic hinges. These regions (plastified zones in structural members) develop at the points of maximum bending moment and cause a change in the scheme of elastic moments. The usual outcome is a reduction in the values of the negative moments in the regions of plastic hinges and a growth in the values of positive moments after those calculated for elastic analysis.

This work describes an experimental study carried out to analyse the capacity for plastic rotation in high-strength reinforced concrete beams subjected to pure bending in the failure zone. The study is important because it is necessary for such behaviour to be clearly defined and properly established before high-strength concrete can be used with complete confidence in structural members.

\section{PREVIOUS STUDIES}

It is known that the rotation capacity in the critical sections of structural members is an important property for the capacity to redistribute forces and for the preven- tion of progressive structural collapse. Despite the apparent brittleness of high-strength concretes, in comparison with normal-strength concretes, the first tests carried out on beams (carried out by Leslie et al., 1976 [7]) in this area have not confirmed this possible brittleness. In fact, some subsequent studies by other authors, such as those published by Shah and Ahmad [10], suggest that the ductility of beams made from high-strength concrete is sufficiently adequate to the necessary seismic resistance, as long as specified limits for certain parameters are respected, such as the longitudinal tensile reinforcement ratio of the beams.

The first studies on the ductile behaviour of highstrength concrete beams were conducted on simply supported beams under incremented static loads, subjected to pure bending in the failure zone. The variables used in these tests were the compressive strength of the concrete, the percentage of the longitudinal tensile reinforcement ratio, the spacing of the compressed concrete reinforcement confinement (transversal reinforcement) and the percentage of longitudinal compression reinforcement.

The first studies by Leslie et al., in 1976 [7], referred to above, concerned the ductile behaviour of highstrength concrete beams subjected to pure bending in the failure zone. They showed the influence of these parameters on that behaviour. Later studies, such as those by Tognon et al. in 1980 [16], Pastor et al., 1984 [9], Naaman et al., 1986 [8], Shin, 1986 [12], Shin et al., 1989 [13], Shin et al., 1990 [14], Lambotte and Taerwe, 1990 [6], Hansen and Tomaszewicz, 1990 [4], Ahmad and Barker, 1991 [2] and Shehata and Shehata, 1996 [11] confirm those conclusions.

If the studies are in good agreement generally, doubts still exist regarding the influence of the strength of the concrete on ductility. Some authors, such as Tognon et al., 1980 [16], Pastor et al., 1984 [9] and Shin et al., 1990 [14], suggest that beams gain in ductility inasmuch as the compressive strength increases. Others authors, like Ahmad and Barker, 1991 [2] and Shehata and Shehata, 1996 [11], say the exact opposite. Yet others, such as Leslie et al., 1976 [7], find that the tendency is not clear, or simply that there is no influence. With regard to the effect of the longitudinal tensile reinforcement ratio, there seems to be a consensus among all authors that ductility decreases as this ratio increases. However, no appropriate limit for this ratio has yet been defined.

An important conclusion relative to the quantification of ductility emerges from what has already been said: there is no "expression" accepted by everyone. Since ductility is directly related to the rotation capacity of the critical sections, the problem stated above also applies to this latter property.

\section{EXPERIMENTAL PROGRAMME}

Destructive tests were performed on nine beams measuring 3.00 metres in length and having an average cross-section of $12 \times 27 \mathrm{~cm}$. The beams were supported simply and subjected to a symmetrical load comprising 


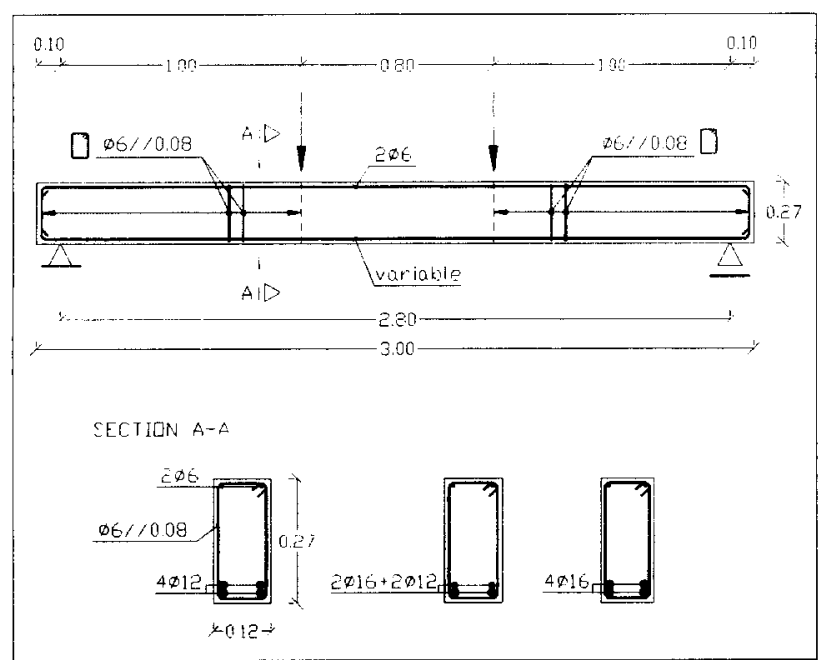

Fig. 1 - Geometry and details of test specimens.
Table 1 gives a summary of the geometrical and mechanical properties of each beam; width (b) and height (h) of the cross-section, effective depth (d), compressive strength obtained for the respective concrete $\left(f_{c}\right)$, modulus of elasticity of the concrete $\left(E_{c}\right)$, area of longitudinal tensile strength $\left(A_{s}\right)$ and the respective reinforcement ratio, $\rho$ and $\rho_{b}$, as well as their ratio $\left(\rho / \rho_{b}\right)$. The real dimensions of the cross-section of the beams suffer slight deviations relative to the average measurements given above. These deviations were due to small displacements occurring in the lateral plates of the formwork during concreting and vibrating. The real dimensions of the beams were assumed when the results were processed. The modulus of elasticity of the concrete, $E_{c}$, at the time when the beams and specimens were tested was calculated theoretically using the expression proposed by Taerwe [15].

For the purposes of this work the beams were divided into 2 series according to the strength ranges of the concretes. Each beam was designated by the series to which it belonged (A or $B)$, by the compressive strength of the concrete, $f_{c}$, (first number) and by the longitudinal tensile reinforcement ratio, $\rho$, (second number).

The reinforcement ratio, $\rho_{b}$, defined in ACI318 [1], corresponds to the longitudinal tensile reinforcement ratio producing balanced strain conditions. This ratio is used here to permit eventual comparisons with other works that use the $\rho / \rho_{b}$ ratio to characterize the amount of longitudinal tensile rein1) $E_{c}=22\left[\left(f_{c k}+8\right) / 10\right]^{0,3}\left(f_{c k}\right.$ in $\left.M P a\right)$ 2) $\left.A_{s}(4 \phi 12)=4.52 \mathrm{~cm}^{2} ; A_{s}(2 \phi 12+2 \phi 16)=6.28 \mathrm{~cm}^{2} ; A_{s}(4 \phi 16)=8.04 \mathrm{~cm}^{2} ; 3\right) \rho=A_{s} /$ bd forcement in the beams.

The compressive strength of the concrete was determined by means of comtwo equal concentrated forces placed approximately at thirds of the span. A sufficiently long central region submitted, in theory, to pure bending was thus obtained. Failure of the beams always occurred by bending in the central zone, between the applied forces.

Fig. 1 gives a schematic representation of the geometry and the details of the beams used in this work. A transverse reinforcement composed of ties placed close together ( $\phi 6$ stirrups $8 \mathrm{~cm}$ apart) was used to prevent shear failure outside the central zone of the beams. No transverse reinforcement was used in the region between the points where the load was applied so that the concrete was not confined in the failure region that was, theoretically, under pure bending. This was one of the hypotheses for this work.

The longitudinal tensile reinforcement comprised hot-rolled steel ribbed bars. The solutions of the reinforcements used were as follows (see Fig. 1): $4 \phi 12,2 \phi 16$ $+2 \phi 12$ and $4 \phi 16$. Two $\phi 6$ bars were placed on the upper side of the beams to provide constructive reinforcement. Since the area of the $2 \phi 6$ bars is very small, the influence of this reinforcement in the compression zone of the section was not taken into account. pression tests performed on specimens. Cube-shaped specimens were used (with a $15 \mathrm{~cm}$ edge), concreted and tested at the same time as the corresponding beam. Core sampling was also carried out for some beams, after they had been tested, with the aim of confirming certain of the results obtained with the concrete specimens. The treatment of the results from the core samples followed UK standard BS1881 [3].

The beams in the first series (A) were made from concrete supplied commercially, while that for the beams in the second series (B) was mixed in the laboratory. Table 2 gives the composition of the concretes mixed in the laboratory. Beams $\mathrm{B}(82.9-2.11)$ and $\mathrm{B}(83.6-2.69)$ were concreted with Mix 2 concrete, and Beams $\mathrm{B}(83.9-2.16)$ and $\mathrm{B}(83.4-2.70)$ used Mix 1. After the formwork was removed, the beams and respective specimens were cured in humid conditions.

Tensile tests were carried out in the laboratory on steel specimens. Table 3 gives the results of these tensile tests, namely the average values for yield stress $\left(f_{y}\right)$, first yield strain $\left(\varepsilon_{\mathrm{y}}\right)$, and the stress corresponding to the maximum force $\left(f_{t}\right)$.

Fig. 2 shows a diagram of a beam in the test position 


\begin{tabular}{|c|c|c|c|}
\hline \multicolumn{4}{|c|}{ Table 2 - Mix design } \\
\hline & & Mix design & ent per $\mathrm{m}^{3}$ ) \\
\hline \multicolumn{2}{|c|}{ Component } & 1 & 2 \\
\hline \multicolumn{2}{|c|}{ Natural Sand (kg) } & 375.00 & 417.00 \\
\hline \multicolumn{2}{|c|}{ Crushed Granite (kg) } & 1245.00 & 1240.00 \\
\hline \multicolumn{2}{|c|}{$\begin{array}{l}\text { Normal Portland Cement } \\
\text { Type l/42.5R (kg) }\end{array}$} & 525.00 & 525.00 \\
\hline \multirow{3}{*}{ Admixture } & Sikament 163 (I) & 1.30 & 1.30 \\
\hline & Sikament FF (I) & 15.75 & - \\
\hline & Rheobuild 1000 (I) & - & 10.50 \\
\hline \multicolumn{2}{|c|}{ Silica Fume (kg) (Sikacrete HD) } & - & 55.00 \\
\hline \multicolumn{2}{|c|}{ Fly Ash (kg) } & 55.00 & - \\
\hline \multicolumn{2}{|c|}{ Water (I) } & 155.00 & 145.00 \\
\hline
\end{tabular}

\begin{tabular}{|c|c|c|c|}
\hline \multicolumn{4}{|c|}{ Table 3 - Tension test results of steel test specimens } \\
\hline Diameter $(\mathrm{mm})$ & $\mathrm{f}_{\mathrm{y}}(\mathrm{MPa})$ & $\varepsilon_{\mathrm{y}}(\mu)$ & $\mathrm{f}_{\mathrm{t}}(\mathrm{MPa})$ \\
\hline$\phi 12$ & 534 & 2672 & 642 \\
\hline$\phi 16$ & 575 & 2876 & 679 \\
\hline
\end{tabular}

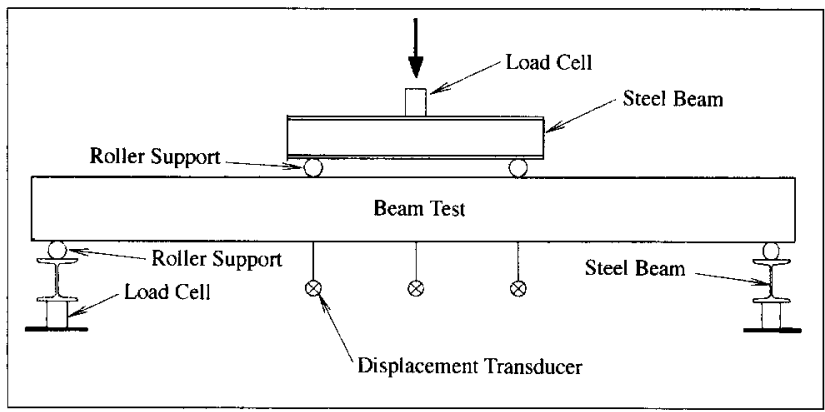

Fig. 2 - Typical set-up for testing beam specimen.

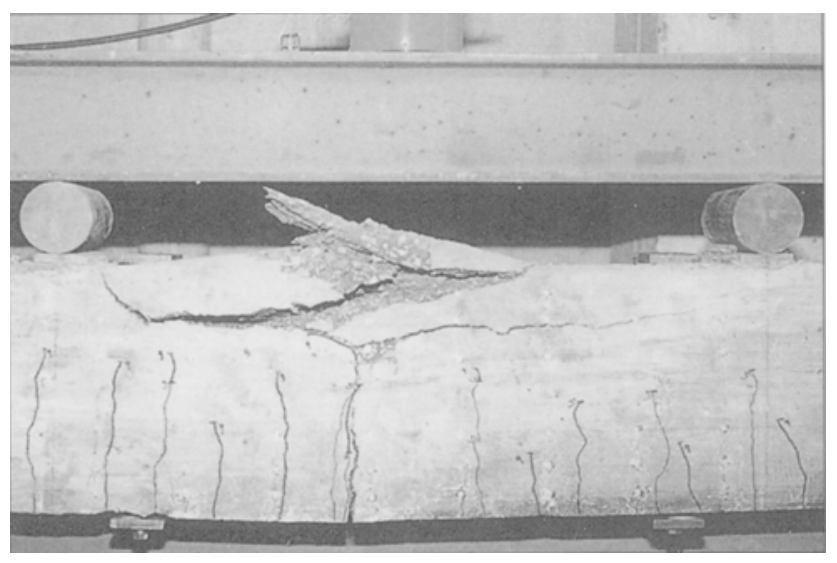

Fig. 3 - Bending type failure.

as well as the location of the exterior measuring instruments. The principal load was applied by means of an electromechanical actuator mounted on the cross beam of a test frame. The load level applied on the beam was measured, at each instant, by load cells. The vertical displacements were measured by means of displacement transducers placed at mid-span and beneath the load points. The strains along the height of the sections in the central zone of the beams were measured by an external grid of Demec targets placed on one of the sides and between the points where the loads were applied. The evolution of the strains in the longitudinal tensile reinforcements during testing were measured by resistance strain gauges placed in the mid-span zone of the beam.

Fig. 3 displays the type bending failure obtained in the central zone of the beams.

\section{RESULTS AND ANALYSIS OF PLASTIC ROTATION CAPACITY}

\subsection{Experimental rotation-deflection graphs}

Figs. 5 to 13 display the Rotation $(\theta)$ versus Deflection $(\delta)$ curves in the failure section for each beam. The experimental curve and theoretical behaviour curves are also shown on these graphs. The latter curves were obtained by an elastic theoretical analysis (with a homogenised section) and a perfect plastic theoretical analysis of the beam. The theoretical elastic curvatures were calculated using the stress and strain diagrams, assuming a state of pure bending acting on the homogenised section of the beams. The theoretical values for the elastic rotations were obtained by multiplying the elastic curvatures by a length of $10 \mathrm{~cm}$. This length, taken as an initial hypothesis and which is very small in comparison with the distance between the support axes of the beams $(2.80 \mathrm{~m})$, coincides with the distance between the columns of Demec targets and is manifested as a very localised length of the beams. In fact, observation of the tests on the beams reveals that their plastification always occurs in a very limited zone, and so it is perfectly legitimate to assume the existence of a local plastic hinge. The theoretical elastic deflections of the beams at mid-span were calculated using tables to calculate the elastic deflections. The modulus of elasticity of the concrete used was that presented in Table 1. To find the plastic theoretical rotations and deflections, a mechanism with a plastic hinge localised in the mid-span section is assumed for the beams (Fig. 4). In fact, the yielding of the reinforcements in the beams tested always occurred in their central zone. The relation between the rotation $(\theta)$ and the deflection at mid-span $(\delta)$ of the mechanism was found by simple geometric relation. The points of the experimental curves $\theta-\delta$ are obtained directly from the experimental values recorded during testing. The experimental rotations, $\theta$, represent the rel-

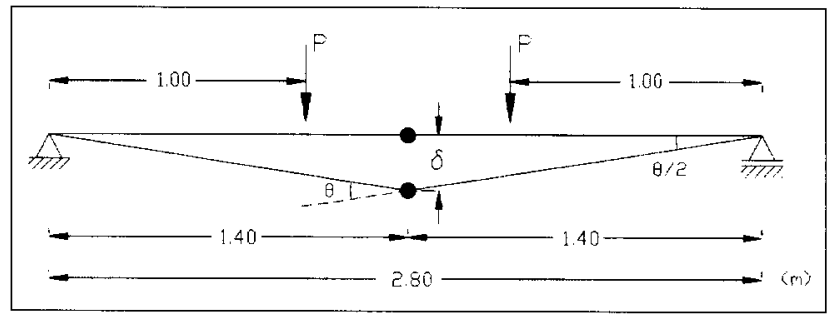

Fig. 4 - Beam mechanism for the plastic analysis. 


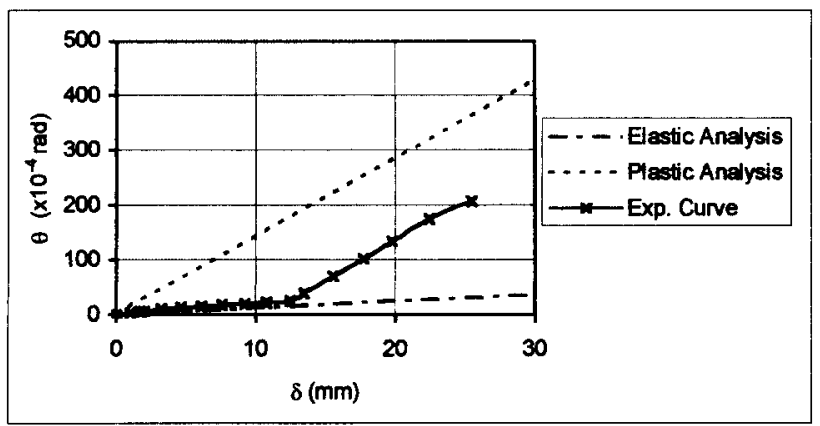

Fig. 5 - Rotation-Deflection Curve (A(62.9-1.52)).

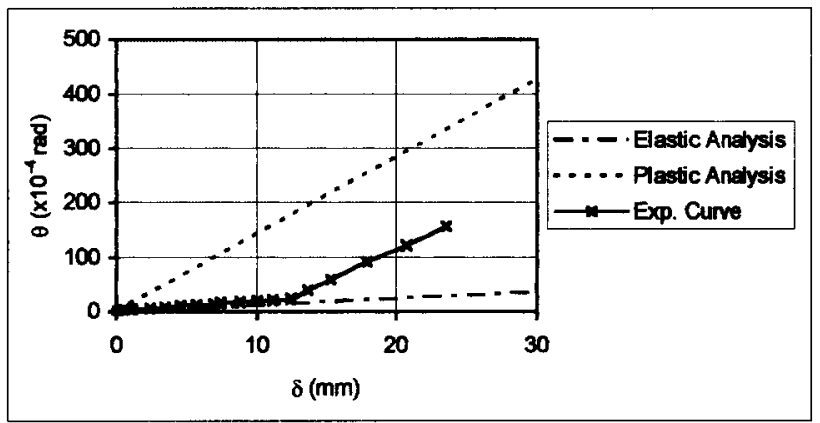

Fig. 7 - Rotation-Deflection-Curve (A(1V-64.1-2.21)).

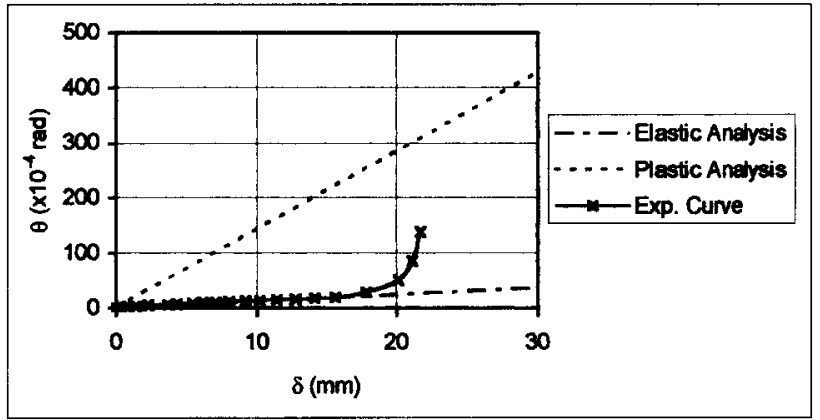

Fig. 9 - Rotation-Deflection Curve (A(65.1-2.86)).

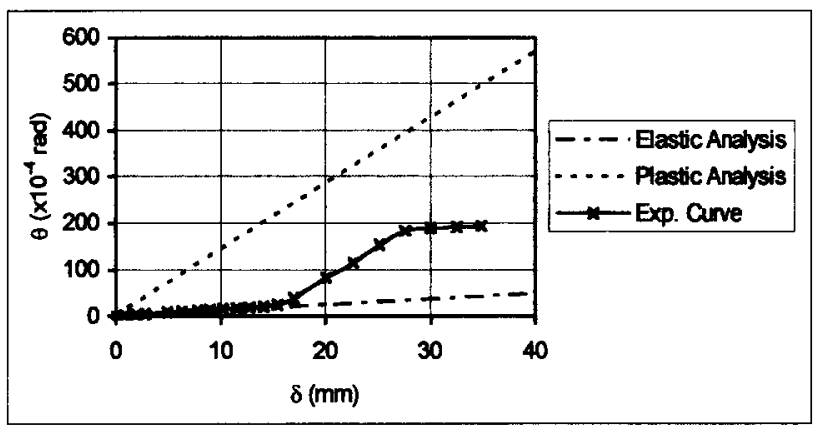

Fig. 11 - Rotation-Deflection Curve (B(83.9-2.16)).

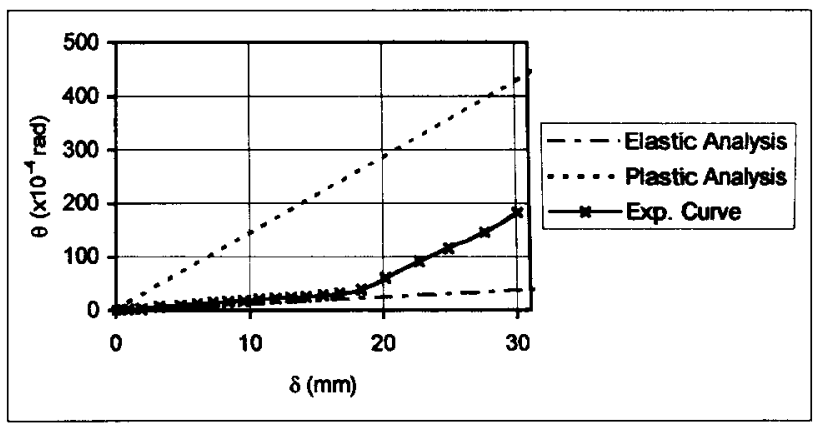

Fig. 13 - Rotation-Deflection Curve (B(83.4-2.70)).

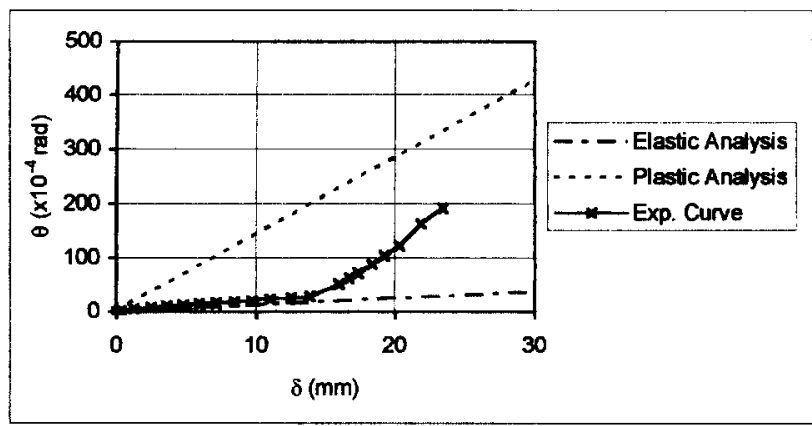

Fig. 6-Rotation-Deflection Curve (A(64.9-2.04)).

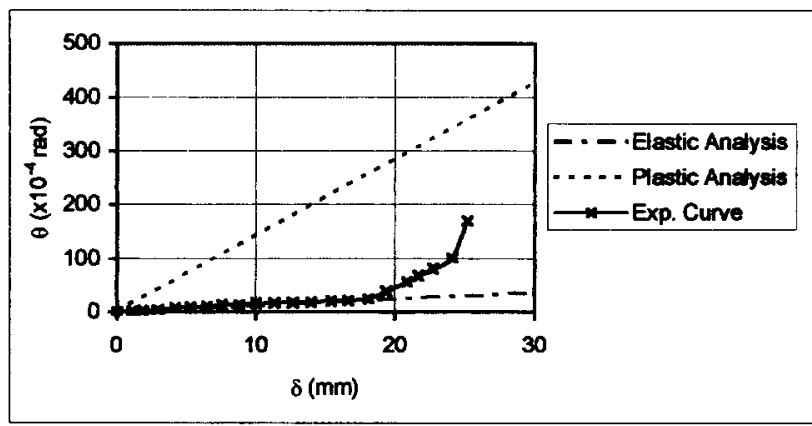

Fig. 8 - Rotation-Deflection Curve (A(63.2-2.86)).

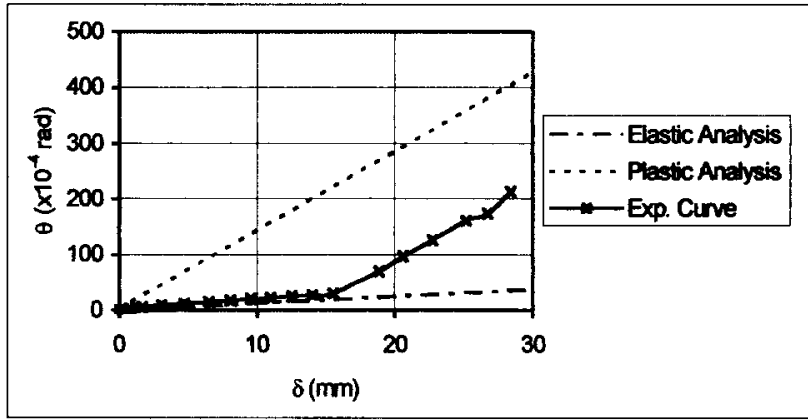

Fig. 10 - Rotation-Deflection Curve (B(82.9-2.11)).

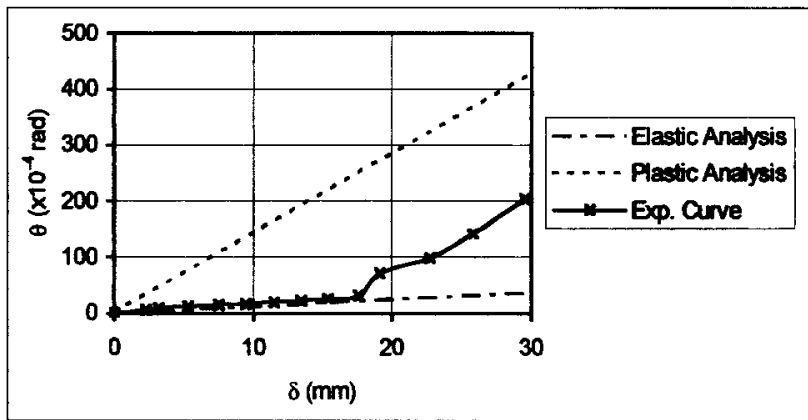

Fig. 12 - Rotation-Deflection Curve (B(83.6-2.69)).

ative rotation between the two surrounding sections, which contain the Demec targets, of the section where failure occurs. These rotations are thus obtained by multiplying the experimental curvature by the distance between the sections referred to $(10 \mathrm{~cm})$, so as to simulate a local plastic hinge, as was done for the elastic theoretical analysis.

Attention is called to the fact that the experimental rotations drawn on the graphs in Figs. 5 to 13 include the elastic and plastic parts of the rotation, and are therefore referred to as total rotations. 
Analysis of the above figures shows that all the experimental diagrams have an initial length where behaviour is perfectly elastic. This zone of the diagram, virtually straight, follows the slope of the straight line obtained for an analysis on elastic behaviour strictly, with very small, or imperceptible, deviations. The validity of the elastic analysis of the beams carried out in this study is thus confirmed. From the moment when the reinforcements enter into yielding, the rotations increase sharply, so that the $\theta-\delta$ experimental curve increases and approaches the slope of the straight line obtained for a theoretical analysis on the perfect plastic phase. In general, the $\theta-\delta$ experimental curve of the beams develops practically in parallel with the straight line relative to the plastic analysis (with a greater or lesser extension), thus confirming that, in this zone of the diagram, the rotations are incremented in accordance with the plastic model adopted in this work. This proves that the initial hypothesis of taking a $10 \mathrm{~cm}$ length for calculating the rotations is valid. This analysis clearly shows that a perfect plastic hinge is formed in this small $10 \mathrm{~cm}$ length (with greater or lesser capacity for rotation), thus justifying the use of plastic analysis on the beams tested. The last part of the $\theta-\delta$ experimental curve has forms which vary from beam to beam. In some beams, the curve maintains the slope referred to above until the ultimate values for deflection and rotation are reached (for example, Beam A(62.9-1.52)). In others (such as Beam $\mathrm{A}(65.1-2.86)$ ), a sharp increase in rotation causing the experimental curve to rise practically to peak was observed. Other beams, (Beam B(83.9-2.16) for instance) saw the rotation increment decrease, making the tangent of the experimental curve also decrease up to failure. One possible explanation for the first finding is that, at the time when the ultimate points on the $\theta-\delta$ experimental curve (final phase of the test) were being measured, the principal crack opened suddenly because the concrete in the compressed zone was already suffering pronounced micro-cracking. This phenomenon, anticipating the actual failure of the beam, abruptly increases the deformations occurring by compression of the compressed concrete, causing a raised increase in the rotation $\theta$ relative to deflection $\delta$ at mid-span of the beam. Analysis of the experimental values found for the strains in the compressed zone of the concrete in the failure zone seems to corroborate this explanation. For the second finding, it is thought that the decrease in rotation $\theta$ relative to deflection $\delta$ at mid-span of the beam in the last phase of the tests is due to the appearance of other principal cracks in the central zone of the beam, suggesting the appearance of new points of plastification on the reinforcements. This state induces a new kind of deformation (with more than one plastic hinge in the central region), in which the deflection $\delta$ increases a great deal in comparison with the rotation $\theta$ measured only in the central zone of the beam.

Generally speaking, examination of the graphs in the Figs. 5 to 13 seems to show that, for a given range of concrete strengths, the capacity to undergo rotations decreases for beams with a larger longitudinal tensile reinforcement ratio.

\subsection{Analysis of plastic rotation capacity}

\subsubsection{Experimental characterisation of plastic rotation}

We will now study the purely plastic behaviour of the beams tested, by analysing the experimental values for plastic rotation. The intention is also to define a parameter to quantify plastic rotation capacity by comparing the performance of the beams. Such a parameter should be based on the experimental values obtained for plastic rotation. The experimental values of relative rotations between the sections surrounding the failure zone (the sections with the Demec targets), shown in graph form as a function of the mid-span deflection in Figs. 5 to 13, include the elastic and plastic parts of the rotation. In order to study the plastic component alone, the elastic part of the rotation must be eliminated. For this reason, the expressions that relate deflection and rotation, calculated for the analysis of beams in elastic behaviour using the homogenised section, are used to calculate the elastic rotation for each beam and each experimental value obtained for the mid-span deflection. To find the plastic component of the test beams, it is enough to subtract the corresponding elastic theoretical rotation from the experimental values obtained. Use of this method is wholly acceptable since, in the study carried out on the $\theta-\delta$ experimental graphs, it was concluded that, during the elastic phase, the beams perfectly followed the forecasts arrived at through the theoretical analysis on the elastic regime with homogenised section. This procedure made it possible to obtain, for each beam, the $\theta_{\text {plast }}-\delta$ experimental graphs, in which $\theta_{\text {plast }}$ represents the experimental values for plastic rotation. These graphs are presented for each beam in Figs. 15 to 23, with the axes adimensionalised for better interpretation and comparison. The parameters represented in the graphs of the above-mentioned figures are as follows:

- $\theta_{\text {plast: }}$ experimental plastic rotation;

- $\theta_{\text {plast, ult,theor: }}$ ultimate value of plastic rotation;

- $\delta$ : experimental deflection recorded at mid-span of the beam;

$-\delta_{\mathrm{u}}$ : ultimate value of experimental deflection (maximum deflection).

The ultimate theoretical value of plastic rotation, $\theta_{\text {plast,ult,theor, }}$ is obtained from the theoretical analysis carried out in the plastic phase and represents the plastic rotation obtained for the ultimate experimental value observed (maximum value) for deflection at mid-span of the beams.

The graphs in Figs. 15 to 23 again show a straight line with reference to the theoretical plastic analysis of the beams, which corresponds to the straight, hatched line in the graphs in Figs. 5 to 13 (Plastic Analysis). The straight line that refers to the analysis on elastic behaviour of the beams that appear in Figs. 5 to 13 (Elastic Analysis) is not given in Figs. 15 to 23, since the elastic component of the rotation has been removed from this analysis.

On the basis of the graphs displayed in Figs. 15 to 23, two parameters termed $\mathrm{C}_{\text {plast,exp }}$ and $\mathrm{C}_{\text {plast, theor }}$ are defined in this work. These two parameters represent, respectively, the area of the plastic rotation graph versus 


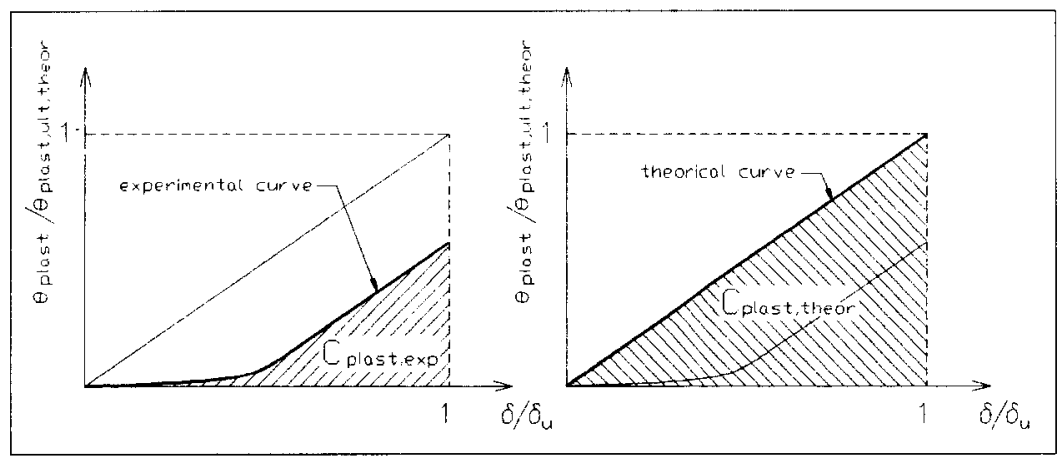

Fig. 14 - Definition of parameters $C_{\text {plast,exp }}$ and $C_{\text {plast,theor }}$.

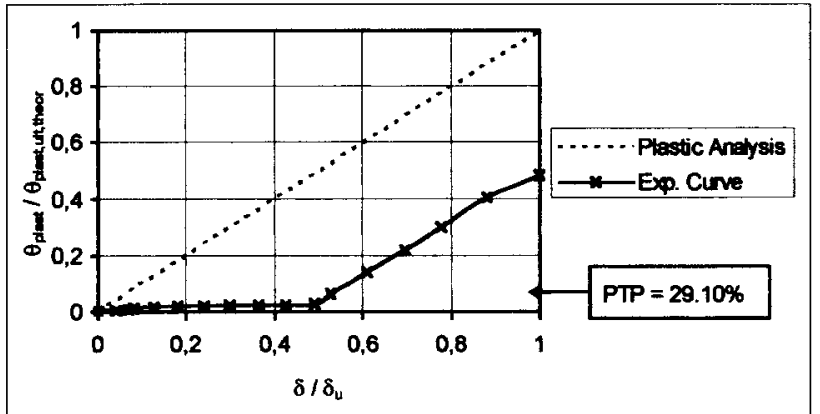

Fig. 15 - Plastic Rotation-Deflection Curve (A(62.9-1.52)).

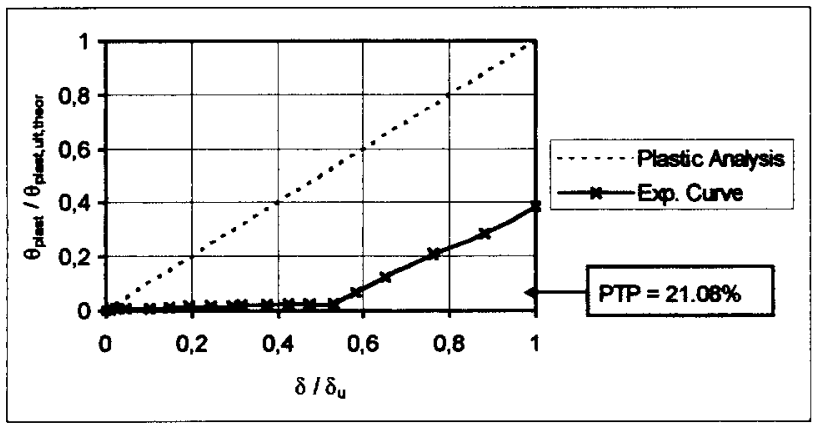

Fig. 17 - Plastic Rotation-Deflection Curve (A(64.1-2.21)).

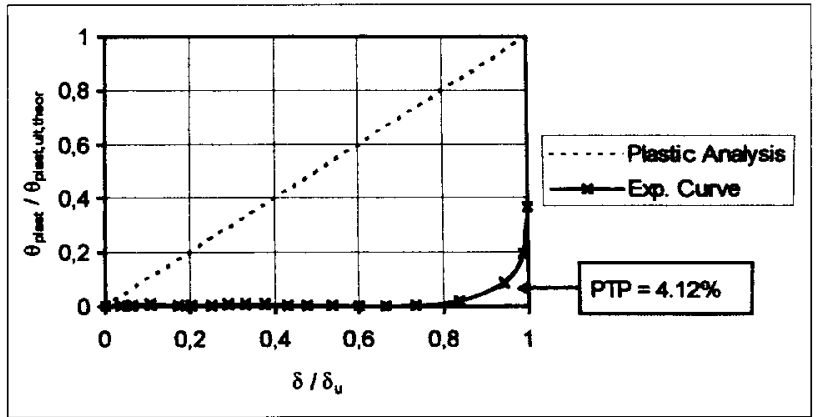

Fig. 19 - Plastic Rotation-Deflection Curve (A(65.1-2.86)).

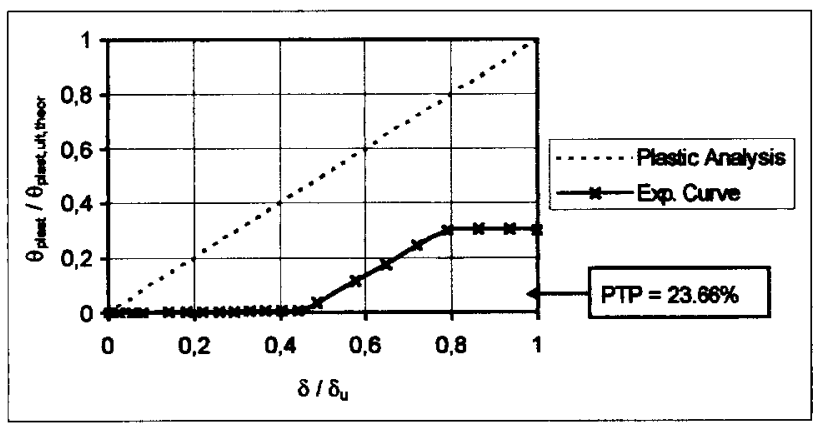

Fig. 21 - Plastic Rotation-Deflection Curve (B(83.9-2.16)). deflection limited by the experimental curve, and the area of the same graph limited by the straight line relating to the plastic theoretical analysis. The definition of these parameters is illustrated in Fig. 14, through which it can also be concluded that the value of parameter $\mathrm{C}_{\text {plast,theor }}$ is constant and equal to 0.5 , since it corresponds to the area of a right-angled triangle with unit cathetus. The areas mentioned are calculated directly from the graphs presented in Figs. 15 to 23.

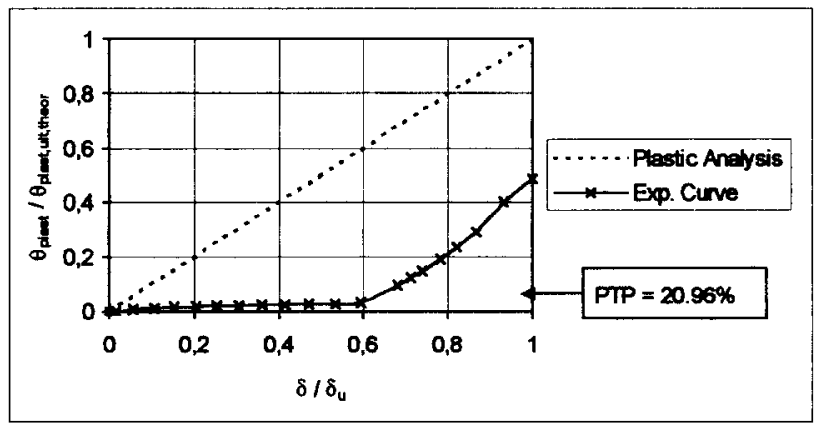

Fig. 16 - Plastic Rotation-Deflection Curve (A(64.9-2.04)).

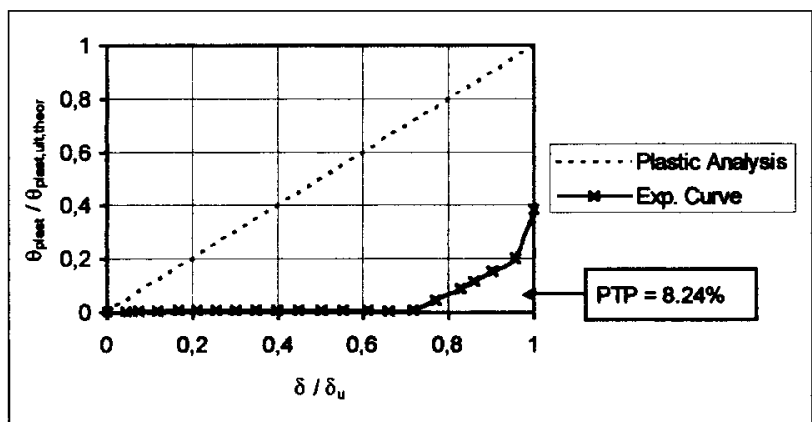

Fig. 18 - Plastic Rotation-Deflection Curve (A(63.2-2.86)).

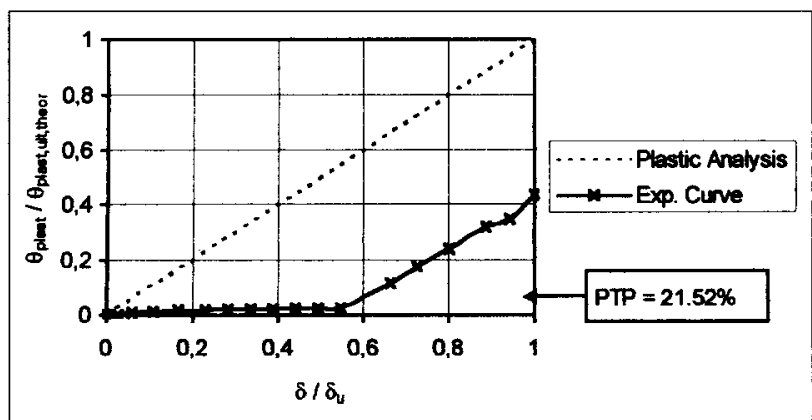

Fig. 20 - Plastic Rotation-Deflection Curve (B(82.9-2.11)).

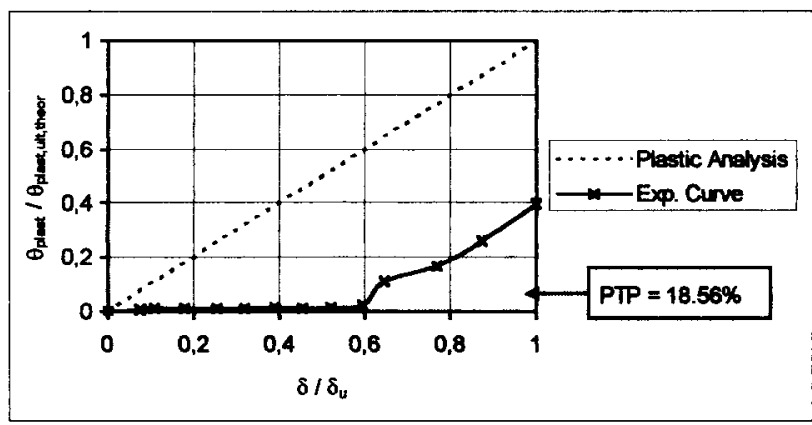

Fig. 22 - Plastic Rotation-Deflection Curve (B(83.6-2.69)). 


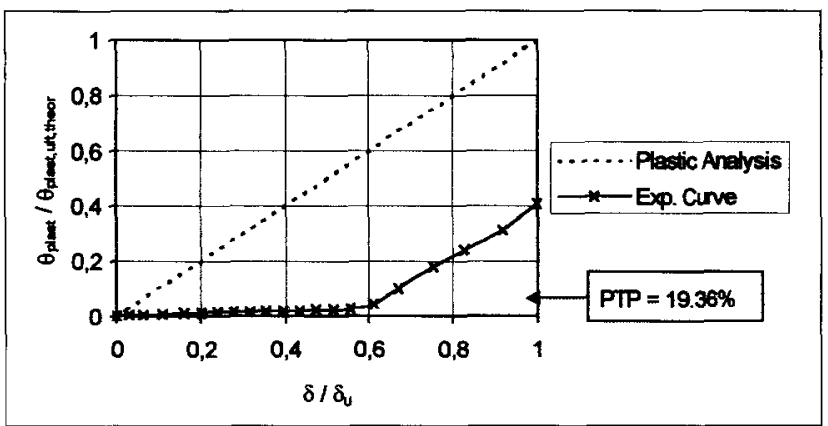

Fig. 23 - Plastic Rotation-Deflection Curve (B(83.4-2.70)). $\rho_{b}$, the $\rho / \rho_{b}$ relation, the compressive strength of the concrete, $\mathrm{f}_{c}$, and PTP (in percentage) that characterises the plastic rotation capacity. In each group the beams appear in increasing order of concrete strength.

Analysing the column of values, in Table 4, for PTP and for Groups 2 and 3, we can say that there seems to be a tendency for PTP to grow with increasing concrete strength. This trend is quite marked in Group 3.

The evolution of the plastic rotation capacity (characterised by PTP) as a function of concrete strength $\left(\mathrm{f}_{c}\right)$ may be seen in graphic form in Figs. 24 and 25, for Groups 2 and 3 (groups with the greatest number of beams), respectively. Each graph also gives a trend line (calculated by linear regression) to emphasise the evolution of PTP. Analysis of the graphs in Figs. 24 and 25 corroborates the earlier analysis carried out using Table 4 , that is, there seems to be a general tendency for the plastic rotation capacity to increase as concrete strength increases. Such increase seems to be fairly pronounced insofar as the longitudinal tensile reinforcement ratio increases.

These tendencies would seem to confirm the findings of Shin et al. [14], Tognon et al. [16] and Pastor et al. [9] with respect to the evolution of ductility in the beams with concrete strength. Indeed, as ductility is related to rotation capacity, if this latter increases with increasing concrete strength, ductility is bound to increase. The results do, however, contradict those of Ahmad and Barker [2] and Shehata and Shehata [11]. The studies cited characterise ductility by means of ductility indexes.

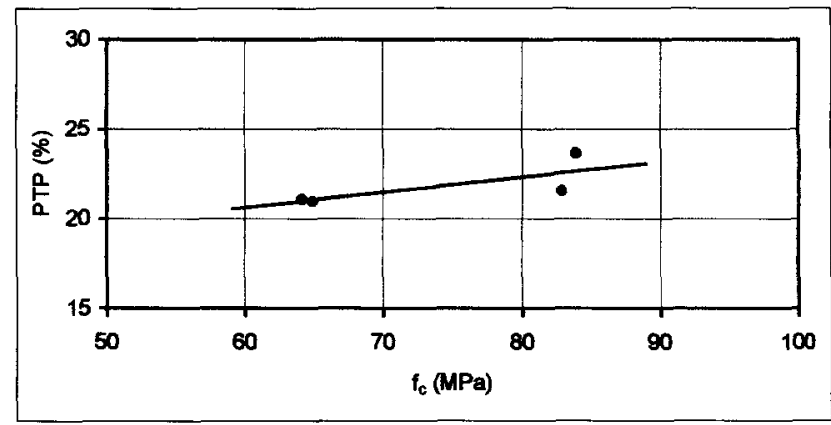

Fig. 24 - Influence of concrete strength on plastic rotation capacity (Group 2: $\left.\rho_{m}=2.10 \% ;\left(\rho_{m} / \rho_{b}\right)_{m}=0.53\right)$.

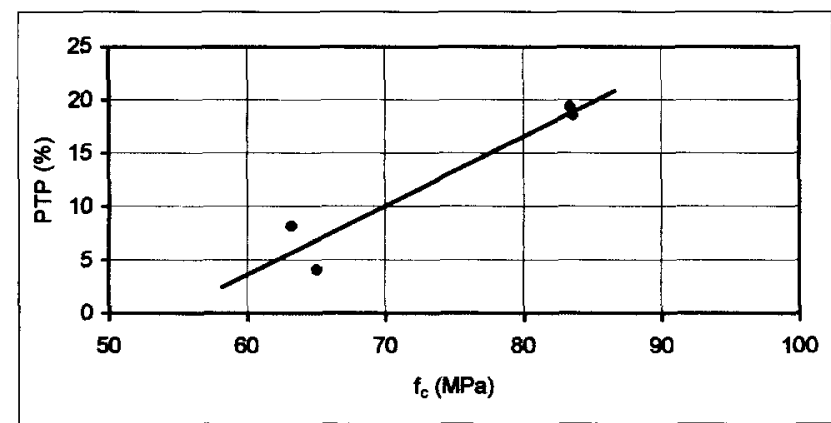

Fig. 25 - Influence of concrete strength on plastic rotation capacity (Group 3: $\left.\rho_{m}=2.76 \% ;\left(\rho_{m} / \rho_{b}\right)_{m}=0.70\right)$.

\subsubsection{Influence of concrete strength on plastic rotation capacity}

To study the influence of concrete strength on plastic rotation capacity, the beams with the same or similar longitudinal tensile reinforcement ratios must be grouped together. Table 4 groups the beams in terms of longitudinal tensile reinforcement ratio $(\rho)$ and gives, for each group of beams, the average values for the longitudinal tensile reinforcement ratio $\left(\rho_{m}\right)$ and the $\rho / \rho_{b}\left(\left(\rho / \rho_{b}\right)_{m}\right)$ relation. For each beam is also given the reinforcement ratio $\rho$ and 


\begin{tabular}{|c|c|c|c|c|c|c|c|}
\hline \multicolumn{8}{|c|}{ Table 5 - Beam groups with similar concrete strength } \\
\hline GROUP & BEAM & $\begin{array}{c}\mathrm{f}_{\mathrm{c}} \\
(\mathrm{MPa})\end{array}$ & $\begin{array}{c}f_{c, m} \\
(\mathrm{MPa})\end{array}$ & $\underset{(\%)}{\rho}$ & $\begin{array}{c}\rho_{b} \\
(\%)\end{array}$ & $\rho / \rho_{b}$ & $\begin{array}{l}\text { PTP } \\
(\%)\end{array}$ \\
\hline \multirow{5}{*}{1} & $A(62.9-1.52)$ & 62.9 & \multirow{5}{*}{64.0} & 1.52 & 3.44 & 0.44 & 29.10 \\
\hline & $A(64.9-2.04)$ & 64.9 & & 2.04 & 3.36 & 0.61 & 20.96 \\
\hline & $A(64.1-2.21)$ & 64.1 & & 2.21 & 3.32 & 0.67 & 21.08 \\
\hline & $A(63.2-2.86)$ & 63.2 & & 2.86 & 3.10 & 0.92 & 8.24 \\
\hline & $A(65.1-2.86)$ & 65.1 & & 2.86 & 3.19 & 0.90 & 4.12 \\
\hline \multirow{4}{*}{2} & $\mathrm{~B}(82.9-2.11)$ & 82.9 & \multirow{4}{*}{83.5} & 2.11 & 4.29 & 0.49 & 21.52 \\
\hline & $B(83.9-2.16)$ & 83.9 & & 2.16 & 4.34 & 0.50 & 23.66 \\
\hline & $B(83.6-2.69)$ & 83.6 & & 2.69 & 4.10 & 0.66 & 18.56 \\
\hline & $\mathrm{B}(83.4-2.70)$ & 83.4 & & 2.70 & 4.09 & 0.66 & 19.36 \\
\hline
\end{tabular}

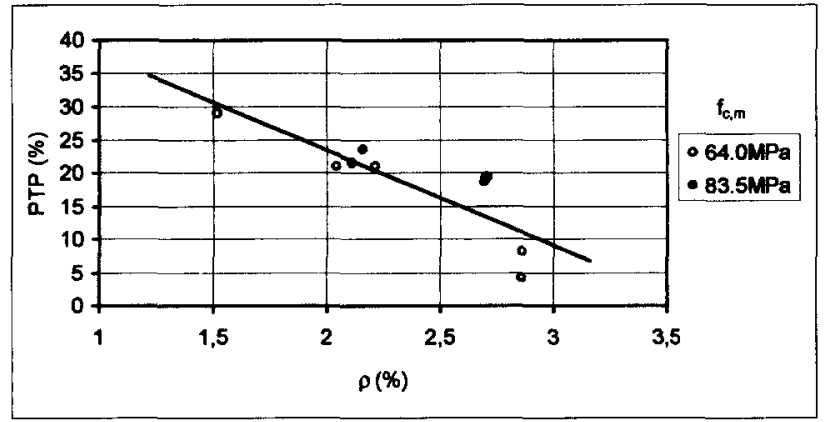

Fig. 26 - Influence of longitudinal reinforcement ratio on plastic rotation capacity.

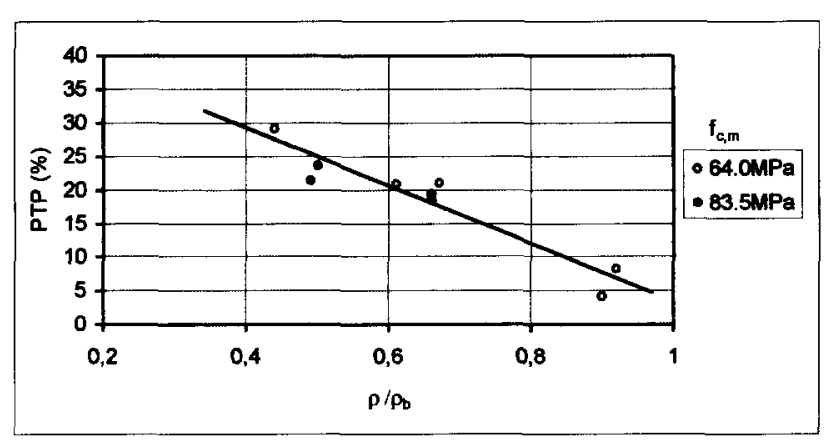

Fig. 27 - Influence of ratio $\rho / \rho_{b}$ on plastic rotation capacity.

This observed tendency can be explained by the fact that, for the same reinforcement ratio, the depth of the neutral axis on failure decreases as the concrete strength increases, giving rise to a tendency for ductile failure to form. This decrease in neutral axis depth on failure appears to compensate for the loss of ductility in the high-strength categories of concrete. This seems to prove that a rational use and combination of highstrength concrete and steel eliminates the apparent brittleness of the material.

\subsubsection{Influence of the longitudinal tensile reinforce- ment ratio on plastic rotation capacity}

Beams with concrete of the same or similar compressive strength must be grouped together to study the influence of the longitudinal tensile reinforcement ratio on plastic rotation capacity. Table 5 displays the groups of beams in terms of the concrete strengths. The same table gives, for each beam, the value of the longitudinal tensile reinforcement ratio $\rho$ and $\rho_{\mathrm{b}}$, the $\rho / \rho_{\mathrm{b}}$ relation and the values for PTP. Table 5 also shows the average concrete strength $\left(f_{c m}\right)$ for each group. In each group, the beams are listed in order of increasing longitudinal tensile reinforcement ratio $(\rho)$.

Examination of the column of values obtained for PTP shows that, in general, plastic rotation capacity falls as the longitudinal reinforcement ratio rises.

Figs. 26 and 27 display the evolution of PTP in graph form, as a function of the longitudinal tensile reinforcement ratio, $\rho$, and the $\rho / \rho_{b}$ relation. The graphs in these figures include the results for all the groups, independently of concrete strength. Care was taken, however, to distinguish the points on the graphs with respect to the different groups of beams (identified by average concrete strength). A linear regression line has been drawn to highlight the evolution of PTP. Through Figs. 26 and 27 the elevated reduction of the plastic rotation capacity with the increase in longitudinal reinforcing ratio is graphically confirmed.

When these results were compared with those in the previous section, the longitudinal reinforcement ratio seemed to be the parameter that most influenced plastic rotation capacity, and hence the ductility of the beams. This agreed with studies by other authors, such as Shehata and Shehata [11], Tognon et al. [16], Leslie et al. [7] and Pastor et al. [9], which all employed ductility indexes. These studies also showed a considerable reduction in ductility indexes insofar as the longitudinal tensile reinforcement increase up to a certain value. After this value, the results of the above-mentioned authors suggest that the ductility indexes for the beams being studied tend towards an approximately constant value. There does seem to be a limit to the longitudinal tensile reinforcement ratio beyond which the values of the ductility indexes are practically the same. Such a behaviour was not found in this work, which used PTP to characterise plastic rotation capacity. We believe that a greater number of beams would be required to confirm this behaviour using the methodology employed in this work.

\section{CONCLUSIONS AND RECOMMENDATIONS}

There does not seem to be any doubt that the parameter that has most influence on the ductility of the beams is the longitudinal tensile reinforcement ratio. This is confirmed from the analysis of the ductility indexes for characterising the ductile behaviour of the beams (works by several authors cited in this paper) and from the analysis of the plastic behaviour, which was done in this work by defining a characterising parameter for plastic rotation capacity (Plastic Tendency Parameter-PTP). For approximately constant values of concrete compressive strength, these experimental results indicate a reasonable reduction in the rotation capacity of the beams with increasing longitudinal reinforcement ratio.

The values of the characterising parameter for plastic 
rotation (PTP) for the beams tested in this work do not seem to tend towards to an approximately constant value, inasmuch as the longitudinal reinforcement ratio increases, apparently uninfluenced by the concrete strength $\left(f_{c}\right)$. This behaviour has been reported in previous studies, already cited, which used ductility indexes as the method of analysis. Confirmation of this tendency does seem to indicate that there is a limit to the longitudinal tensile reinforcement ratio after which ductility practically stops decreasing, regardless of the compressive strength of the concrete. It will, however, be necessary to carry out further studies to complete the current results, with the aim of determining whether there is such a tendency, based on the methodology used in this work.

The compressive strength of the concrete seems to have quite a variable influence on the rotation capacity of the beams, for approximately constant reinforcement ratios. Our results show that, in general, for similar reinforcement ratios, an increase in the compressive strength of the concrete leads to an increase in rotation capacity, which agrees with some authors and contradicts the findings of others. This increase seems to be accentuated as the longitudinal tensile reinforcement ratio increases. Thus, although high-strength concrete is a less deformable material than normal-strength concrete, the results appear to suggest that the rotation capacity of a reinforced concrete section grows with the compressive strength of the concrete, for the same longitudinal tensile reinforcement ratio value. This apparent contradiction can be readily understood if it is recalled that maintaining the reinforcement ratio, the beams made with stronger concrete exhibit lower values of $\mathrm{x} / \mathrm{d}$ on failure (where $\mathrm{x}$ is the depth of the neutral axis), making the failure of the section more ductile. Acceptance and clarification of this behaviour in high-strength concrete must therefore depend on the outcome of further studies to confirm it.

In the phase of the behaviour of the beams prior to the yielding of the reinforcements, the experimental results obtained from the rotation-deflection behaviour graphs $(\theta-\delta)$ show good agreement with the theoretical analysis in the elastic regime, performed in this work. After the yielding of the reinforcements, the beams develop a behaviour for which the rotations are, in general, incremented in accordance with the theoretical plastic analysis performed in this work. The formation of a perfect plastic hinge, situated in a small length, is thus imputed (the hypothesis assumed for the theoretical plastic analysis). Such behaviour develops along a determined deformation platform which is larger as the plastic rotation capacity of the beam is larger. This behaviour thus confirms that the use of plastic analysis is sufficient to study the beams tested in this work.

The parameter developed to analyze the behaviour in the plastic phase of the beam (PTP) seems to characterize their plastic rotation capacity perfectly. The study carried out using this parameter generally confirmed the most important tendencies observed for the behaviour by previous analyses, which used ductility indexes.

This work raised one question that could not be fully elucidated. It concerns the influence of concrete strength and its importance in rotation capacity. The reason for the existence of the contradictory results in the various research works that have focused on this topic must be discovered so that the problem can finally be definitively resolved.

\section{ACKNOWLEDGEMENTS}

We are grateful to the Department of Civil Engineering, University of Coimbra, for making available the human and material resources needed to carry out this work. We would also like to thank the Portuguese Foundation for Science and Technology for the support given through research project POCTI/ $\mathrm{ECM} / 33642 / 99$.

\section{REFERENCES}

[1] ACI Committee 318, Building Code Requirements for Reinforced Concrete, (ACI 318-89) and Commentary (ACI 318R-89), American Concrete Institute, Detroit, MI, 1989.

[2] Ahmad, S. H. and Barker, R., 'Flexural behaviour of reinforced high-strength lightweight concrete beams', $A C I$ Structural Joumal 88 (1) (January-February 1991) 69-77.

[3] British Standard BS 1881, Part 120, 'Method for Determination of the Compressive Strength of Concrete Cores', 1983.

[4] Hansen, E. A. and Tomaszewicz, A., 'Effect of confinement on the ductility of structural members with high strength concrete', SINTEF Report STF65 F90071, Trondheim 1990, 184-191.

[5] Khaloo, A. R. and Ahmad, S. H., 'Behaviour of normal and highstrength concrete under combined compression-shear loading', ACI Materials Journal 85 (6) (November-December 1988) 551-9.

[6] Lambotte, H. and Taerwe, L. R., 'Deflection and cracking of high-strength concrete beams and slabs', SP 121-7, HighStrength Concrete, Second International Symposium, Weston T. Hester, ACI, 1990, 108-128.

[7] Leslie, K. E., Rajagopalan, K. S. and Everard, N. J., 'Flexural behavior of high-strength concrete beams', ACI Joumal 73 (9) (1976) 517-521.

[8] Naaman, A. E., Harajli, M. H. and Wight, J. K., 'Analysis of ductility in partially prestressed concrete flexural members', $P C I$ Joumal 31 (3) (1986) 64-87.

[9] Pastor, J. A., Nilson, A. H. and Slate, F. O., "Behaviour of highstrength concrete beams', Research Report 84-3, Department of Structural Engineering, Cornell University, Ithaca, New York, February, 1984, $311 \mathrm{p}$.

[10] Shah, S. P. and Ahmad, S. H., 'High Performance Concretes and Applications', Edward Arnold, England, 1994.

[11] Shehata, I. A .E. M. and Shehata, L. C. D., "Ductility of high strength concrete beams in flexure', 4th International Symposium on Utilization of High-Strength / HighPerformance Concrete, Paris, 1996, pp. 945-953.

[12] Shin, S.-W., 'Flexural behaviour including ductility of ultrahigh-strength concrete members', Ph.D. Thesis, University of Illinois at Chicago, Chicago, IL, 1986, 232p.

[13] Shin, S.-W., Ghosh, S. K. and Moreno, J., 'Flexural ductility of ultra-high-strength concrete members', ACI Joumal, Proceedings 86 (4) (July-August 1989) 394-400.

[14] Shin, S.-W., Kamara, M. and Ghosh, S. K., 'Flexural ductility, strength prediction, and hysteretic behavior of ultra-high-strength concrete members', SP 121-13, High-Strength Concrete, Second International Symposium, Weston T. Hester, ACI, 1990.

[15] Taerwe, L., 'Codes and regulations', 4th International Symposium on Utilization of High-Strength / HighPerformance Concrete, Paris, 1996, 93-99.

[16] Tognon, G., Ursella, P. and Coppeti, G., 'Design and properties of concretes with strength over $1500 \mathrm{kgf} / \mathrm{cm}^{2}, A C I$ Journal, Proceedings 77 (3) (1980) 171-178. 